\title{
Research and Exploration of the electronic design contest to promote the reform of experiment teaching
}

\author{
Guoliang Du \\ Southeast University \\ Nanjing, China \\ dugl@seu.edu.cn
}

\author{
Huichun Huang \\ Southeast University \\ Nanjing, China \\ huanghuichun@seu.edu.cn
}

\author{
Renjie Hu \\ Southeast University \\ Nanjing, China \\ hurenjie@seu.edu.cn
}

\begin{abstract}
The paper analyzes the characteristics of electronic design contest, and deficiencies of the electronic information professional practice curriculum. Use the issues-based, project-based and case-based engineering education philosophy and teaching methods as orientation. By optimizing the teaching system and content, electronic design contest and reform of experiment teaching could support and promote each other and improve students' practical and innovative ability.
\end{abstract}

Keywords- National Undergraduate Electronic Design Contest;Practical Teaching Reform;Teamwork

\section{INTRODUCTION}

National Undergraduate Electronic Design Contest (NUEDC) [1] is co-sponsored by the Department of Higher Education of Ministry of Education and Ministry of Information Industry, from the beginning of 1994, a biennial event, which lasted 20 years, each year to participating schools and teams are on the rise. In 2011 there were 10,972 teams from 1,042 schools participated across the country. NUEDC is the longest-held, largest, most influential college students discipline contest in the field of China's electronic information [2].

Southeast University (SEU) has about 40 teams from 9 faculties of electronic information. Excellent result had been achieved in the previous race. To make the competition better service to the teaching, and students have the practical ability, teamwork and innovating spirit, research and reform were made through a lot of exploration and study work.

\section{ANALYSIS OF THE CURRENT SITUATION}

NUEDC is the integration of multiple disciplines. Its content related to multiple curriculums and courses like computer technology, electronic technology, control theory, sensor technology and communication technology. NUEDC held in early September of the contest years. The majority of participating students are the senior and junior. The contest requires participating students in groups of three, in the time of four days and three nights to complete the process as follows: "topic selection $\rightarrow$ inquiring information $\rightarrow$ argument $\rightarrow$ hardware and software design $\rightarrow$ components selection $\rightarrow$ assembly production $\rightarrow$ tuning and test $\rightarrow$ report writing”. Both the breadth and depth of knowledge involved, the integrated applying of multi-disciplinary knowledge and practical capability are very challenging [3]. Their teaching requirements for students are far from being simply a course that can be achieved [4].
The laboratory curriculum arrangement in general colleges were set up around the theory courses. No matter the theory and laboratory courses were scheduled together or separately, the main contents of experiments corresponded with the requirements of the theory courses. The biggest advantage of this arrangement was that the experiments verify the theory. It was good for understanding and mastering the relevant theoretical knowledge points, but the following problems were also presence:

- Each curriculum carried out experimental teaching around the syllabus of its own. The link between the curriculums was absence. The lack of the overall concept of the project made the lack of the integrated system design capabilities of students;

- Many of the experiments were designed only to correspond with some point of knowledge and lacked of engineering background or practical value. Students could not understand the real meaning of the experimental data. And the concept of function of the project and performance indicators was not established. Experiment was difficult to stimulate students' interest in learning. Students were also difficult to enjoy the fun of success;

- Limited hours were assigned to a different course experiments. Each experiment emphasized its own basic requirements which are commonly 2 to 3 hours. It was difficult to set gradient for project in depth and difficulty. The students just glimpsed in the experiment, and were difficult to have space of improve;

- With the rapid development of electronic technology, the update of basic experiment content was much slower than the development of new technology, devices and design methods. It is necessary to guide students in the experiment to independently study, query with the use of network resources to achieve learning by doing and learning in research.

\section{IMPLEMENTATION}

\section{A. Building hierarchical experiment teaching system}

The trainings of practical innovation ability are throughout the whole process of experiment teaching. The trainings consist of a series of interrelated teaching activities and follow the principle of gradual and orderly progress. By learning the knowledge and training corresponding ability, the leap from accumulating of basic knowledge to the fusion 
of comprehensive knowledge and the capability of innovative.

The entire capacity training was divided into three stages in specific implementation:

1) Engineering practice basic training, which stage was for the first and second grade students. Following courses were involved: basic electric and electronic experiments, circuit experiments, digital circuit experiments, analog circuit experiments, and electric and electronic technology experiments. The purpose is to help students to establish learning objectives, stimulate learning motivation and interest in learning and strengthen the basic skills of engineering and build platform of engineering practice for innovation.

2) The practical application of engineering. This was based on adequate training in the first stage and for the sophomore and junior. The courses corresponded were: PLD experiments, MCU experiments, embedded systems experiments, sensor application experiments, and the control technology experiments. The purpose is to train the students 'ability to acquire new devices, technologies and method. The experiments focus on training students of design capability.

3) The comprehensive implementation of engineering. For junior and senior students, the corresponding courses are : digital system design and comprehensive electronic system design. The purpose is to teach students using of all kinds of knowledge flexibly, and train the students` innovation design capabilities of project-oriented with engineering background. This could implement the leap of creative abilities from passive receiving to active discovery.

\section{B. Establishing thematic seminars}

The content of previous NUEDC can be summarized into the following classes: electric power, radio, instrumentation, data acquisition and control. At the same time of basic courses of electronic information, seminars in multi-level, multi-field and multi-directional were established: such as the analog signal conversion and processing, sensors and signal conditioning, small signal measurement, measurement and control circuit design, DC-DC transform as well as electronic circuit experiment of innovation. Every seminar, apart from a brief theoretical knowledge, focused on the expansion of the design concept, design methods and new applications. By those experiments, students were guided to challenge some difficult issues in the professional areas.

The seminars trained students`ability at finding and solving the problem, and summing up experiences. Students could launch the relevant research topic and carry out the various NUEDC and students research projects. This developed students' scientific research ability.

\section{Optimizing the content of experiment curriculum}

Both the basic experiments and the seminars were always focusing on the cultivation of students' self-learning ability. Optimization of each content of curriculum gradually improved students' comprehensive design capability and application ability as well as mastering the basic principles, concepts and practice skills. It created the conditions for extracurricular research and deeply carrying out of NUEDC.

Take the electronic circuit experiment as an example: lots of changes from the experiment teaching content were made. The original simple cell experiments were combined to several comprehensive experiments with engineering background. This was for the training of the students system design and engineering application capabilities. The contents of the experiments were divided into fundamental part, raise part and innovation part, in order to meet the requirements of students of different abilities, which also provided a good foundation for selecting students to participate in the NUEDC. Finally, the experimental methods, assessment methods, software and hardware environment were reformed correspondingly to stimulate the students' interest and motivation to learn, cultivate the students' teamwork spirit. Good result in teaching and learning has been appeared with the combination of theory and practice, basic and enhanced, unit and system, virtual and real, individual and teamwork and achievements and ability.

The reform in experiment contents and methods has been made in the honor class of Wu Jianxiong College for 3 years [5]. The students comprehensive experimental ability and self-learning ability has been greatly improved. It has also been generally approved in the surveys of students.

\section{Exploring the engineering teaching method}

Electronic information is a typical engineering discipline. The training of talents must meet the requirements of modern engineering. In the education reform process, it is necessary to strengthen the cultivation of engineering and make students learning about standard development process, and matching with the project as soon as possible.

In the third stage of teaching system, students combine their interest in according disciplines direction and choose a practical application of engineering as experimental design project. The project accomplished after the process of design, circuit implementation, system debugging, checking and acceptance, summary and presentations.

Major requirements were placed on the process of design ideas and actual assembly, emphasizing the engineering practice content like the program analysis, system implementation, debugging and testing, reliability and project management. The implementation of those projects would involve a lot of related knowledge. It required students to master the knowledge and comprehensive application. Students' ability of writing, speaking and teamwork were trained through the usual discussions and seminars. Those also emphasized the culture of innovative thinking, knowledge utilization and engineering practice.

\section{EFFECTIVENESS OF THE REFORM}

After the reform of practice teaching methods and content, the students' interest and enthusiasm are fully mobilized, and actively participate in various Electronic 
Design Contest and extra-curricular science and technology activities. In the 2011`s NUEDC, 3 national first prize and six second prize were achieved by SEU, which had totally 42 teams participated. More than 30 projects were accepted in the 2011 national and provincial undergraduate research training program. And 31 projects were accepted in SRTP. At the same time, the electronic design contest, smart car competition, PLD contest, embedded systems and other competitions were also organized in the campus. Nearly 1000 students participated in those contests each year, which means $60 \%-70 \%$ of student learning electronic information. Students capability in active learning and research improved significantly. In 2011 electronic information professional students received a total of more than 20 national patents, and have published 25 research papers.

Students` self-learning ability and overall quality has significantly improved under the of hierarchical practice teaching system. A lot of them were recommended to graduate school exemption. They showed obvious advantages in specialized courses learning, graduation design, graduate studies and development into the community. They also have been widely welcomed by employers and graduate instructors.

\section{CONCLUSIONS}

After several years of teaching reform, research and exploration, mutual support and promotion between NUEDC and practice teaching reform are taking effect.

The hierarchical practice teaching system is conducive to the students to break the course boundaries and strengthen the integration and use of knowledge. By establishing thematic seminars of different disciplines and backgrounds, experiments and projects with new technologies, new knowledge and new device were merged into the hierarchal practice teaching. This leaded to the continuous training of the students` engineering capability of learning, query, expand knowledge, research and exploration, programs discuss, design simulation, system implementation, debugging and testing, analysis and summary and overall quality.

\section{REFERENCES}

[1] WangYue,HanLi,“National undergraduate Electronic Design Contest and develop students' ability to innovate,”University Teaching in China,n10,p4-6,2005.

[2] Guo,Shunjing, Zhang Haifeng,"National undergraduate electronic design contest and reform of innovative education," Source: 2010 International Conference on E-Product E-Service and E-Entertainment , 2010.

[3] Chen Yuqing,Peng Xiaoshan,Sun Jian, "National undergraduate electronic design contest: A vehicle for enhancing active learning," British Journal of Educational Technology, v41, n4, p660-664, July 2010.

[4] Dai Yahong,Li Hong,Hu, Jianping, “Innovative practices on teaching modes in electronic design skills for information technique students,"Source: Advances in Information Sciences and Service Sciences, v 4, n 19, p 571-579, October 2012.

[5] Huang Huichun,Du Guoliang, Hu Renjie, "Reform and practice of the electronic circuit experiment teaching mode for the purpose of strengthening the electronic system design ability," Source: Proceedings of IEEE International Conference on Teaching, Assessment, and Learning for Engineering, TALE 2012, p W2B7-W2B10, 2012. 